\title{
ESTABELECIMENTO DE PARÂMETROS PARA AVALIAÇÃO DE TOLERÂNCIA À SECA, EM GENÓTIPOS DE FEIJOEIRO'1
}

\author{
CARLOS PIMENTEL ${ }^{2}$ eANDRÉS JERÔNIMO DELACRUZPEREZ ${ }^{3}$
}

\begin{abstract}
RESUMO - Com o objetivo de estabelecer parâmetros para avaliação de tolerância à seca, 15 genótipos de feijoeiro (Phaseolus vulgaris L.) foram monitorados durante a indução de estresse hídrico na préfloração, por meio do potencial hídrico nas folhas $\left(\Psi_{f}\right)$ e de outras variáveis. Os genótipos A 222, A 285, BAT 477, BAT 561 e IPA 7 apresentaram valores de $\Psi_{\mathrm{f}}$ superiores ao dos outros genótipos, durante o estresse, sugerindo um maior controle da abertura estomática. Os genótipos com tolerância à antracnose mostraram possuir este mecanismo de controle, enquanto as cultivares Carioca e Ouro Negro recuperaram-se mais rapidamente, após a reidratação. O potencial de fixação biológica do nitrogênio, avaliado pelo número e peso seco de nódulos, foi significativamente pouco afetado pelo estresse. Quanto aos parâmetros morfológicos, aqueles que sofreram maior efeito do déficit hídrico foram a área foliar e o peso seco da parte aérea. Nos componentes de rendimento, o número de vagens por planta foi afetado somente nos genótipos Xodó e CNF 0145, enquanto os genótipos Carioca, A 285, CNF 0145, BAT 477 e cv. 121 e a linhagem LM 30036 sofreram diminuição no peso de grãos por planta, devido à deficiência hídrica. Dos genótipos estudados, somente A 222 e IPA 7 mantiveram o $\Psi_{\mathrm{f}}$ mais alto do que os outros e não sofreram redução significativa na área foliar e no peso de grãos, apesar de o primeiro genótipo apresentar baixa produção por planta, em condições de estresse.
\end{abstract}

Termos para indexação: Phaseolus vulgaris, deficiência hídrica, potencial hídrico da folha, área foliar, componentes de rendimento.

\section{ESTABLISHMENT OF PARAMETERS FOR WATER STRESS TOLERANCE EVALUATION ON BEAN GENOTYPES}

\begin{abstract}
Aiming to establish parameters for drought tolerance evaluation, fifteen genotypes of bean (Phaseolus vulgaris L.) were evaluated during a water stress period, applied at the pre-flowering stage through leaf water potential $\left(\Psi_{\mathrm{f}}\right)$ and some other variables. Among the genotypes studied, A 222 , A 285 , BAT 477, BAT 561 and IPA 7 showed highest $\Psi_{\mathrm{f}}$ during the water stress, indicating a better stomatal control by these genotypes, while the cultivars Carioca and Ouro Negro showed a more rapid recuperation, after being rehydrated. All the Anthracnose tolerant genotypes evaluated presented an efficient stomatal control. The potential for nitrogen biological fixation, evaluated by the number and weight of nodules, was significantly affected only on few genotypes. Leaf area and shoot dry weight were the morphological variables more sensitive to water stress. The number of pods per plant was only affected on Xodó and CNF 0145 genotypes, while the Carioca, A 285, CNF 0145, BAT 477, cv. 121 genotypes, and the LM 30036 line, showed a decrease on the seed weight per plant, under water stress. Besides having the highest $\Psi_{\mathrm{f}}$, the A 222 and IPA 7 genotypes were the only ones that did not show a significant reduction on the leaf area and seed weight per plant, although the first one had a low plant production under stress.
\end{abstract}

Index terms: Phaseolus vulgaris, water deficit, leaf water potential, leaf area, yield components.

\footnotetext{
${ }^{1}$ Aceito para publicação em 4 de março de 1999.

2 Eng. Agrôn., Dr., Prof. Titular, Dep. de Fitotecnia, Universidade Federal Rural do Rio de Janeiro (UFRRJ), CEP 23851-970 Seropédica, RJ. E-mail: greenman@amcham.com.br

${ }^{3}$ Eng. Agrôn., Dep. de Fitotecnia, UFRRJ. Bolsista de Iniciação Científica.
}

\section{INTRODUÇÃO}

$\mathrm{O}$ estresse hídrico afeta praticamente todos os aspectos do crescimento da parte aérea e da raiz, causando redução na expansão celular, condutância estomática, fotossíntese e conseqüentemente, na 
acumulação de matéria seca (Hsiao, 1990). Na América Latina, em cerca de $93 \%$ da área de cultivo de feijão, a necessidade hídrica da planta, durante o seu ciclo, não é satisfeita (Singh, 1995). A produtividade do feijoeiro é mais afetada pela falta d'água, quando esta ocorre no período de pré-floração, na formação dos botões florais (Fageria et al., 1991).

Vários mecanismos permitem aos vegetais tolerar a falta d'água em maior ou menor intensidade (Subbarao et al., 1995), sendo a adaptação à seca uma função multigênica, e portanto dependente de várias características fisiológicas e morfológicas (Bray, 1993). O feijoeiro apresenta dois principais mecanismos de adaptação à seca, para manutenção de alta hidratação da planta (Kramer \& Boyer, 1995), que são: o controle estomático, diminuindo as perdas de água (O'Toole et al., 1977), e o desenvolvimento do sistema radicular, para maior captação de água (Kuruvadi \& Aguilera, 1990). Esta característica de adaptação à deficiência hídrica favorece o desenvolvimento do sistema radicular, em detrimento ao crescimento da parte aérea, sobretudo quando submetidas à seca (Subbarao et al., 1995). Outra característica morfológica desejável é a duração da área foliar, através da manutenção de alto índice de área foliar após a floração, sobretudo em plantas do tipo I, com hábito de crescimento determinado (Portes, 1996).

O genótipo que mantiver elevado potencial hídrico na folha, comparado aos demais, provavelmente apresenta um dos citados mecanismos de adaptação à seca (Kramer \& Boyer, 1995). Segundo Hsiao (1990), a redução do potencial hídrico da folha durante o estresse hídrico, quando comparado ao controle irrigado, pode ser correlacionada com a queda de produtividade. Outro parâmetro correlacionado com a produtividade é a manutenção da área foliar e, conseqüentemente, a produção de fotoassimilados, quando sob estresse hídrico, sobretudo no período crítico de pré-floração. Blum (1997) recomenda o uso de parâmetros correlacionados com o rendimento da cultura, e de fácil mensuração, ao invés de avaliações tais como a acumulação de prolina, glicina-betaína e deidrina.

O objetivo deste trabalho foi estabelecer parâmetros para avaliação de tolerância à seca de genótipos de feijoeiro.

\section{MATERIAL E MÉTODOS}

Foram avaliados 12 genótipos de feijoeiro, em três experimentos independentes; no primeiro, 2234, A 222, Carioca, Negro Argel e Xodó, conduzido entre setembro e novembro de 1992; no segundo, A 285, CNF 0145, LM 30063, LM 10363 e LM 30036, conduzido entre março e maio de 1993; e no terceiro, BAT 477, BAT 561, Ouro Negro, IPA 7, Xodó e cv. 121, conduzido entre setembro e novembro de 1993. A cultivar Xodó, bastante cultivada no Estado do Rio de Janeiro, foi avaliada em dois experimentos, servindo como referência. As sementes foram obtidas no banco de germoplasma da EmbrapaCentro Nacional de Pesquisa de Arroz e Feijão (CNPAF), exceto a cultivar IPA 7, obtida no Instituto de Pesquisa Agropecuária (IPA), de Pernambuco. Os genótipos foram indicados pelos citados centros de pesquisa, e fazem parte de programas para adaptação de feijoeiro à seca, sendo a única indicação de tolerância à seca reservada à cultivar BAT 477 (Guimarães, 1996).

Os experimentos foram conduzidos em casa de vegetação, no Departamento de Fitotecnia da UFRRJ. As temperaturas médias no ambiente oscilaram entre 32 e $38^{\circ} \mathrm{C}$ no primeiro experimento, 27 e $35^{\circ} \mathrm{C}$ no segundo, e 33 e $42^{\circ} \mathrm{C}$ no terceiro. A umidade relativa do ar variou entre 55 e $75 \%$ no primeiro experimento, 60 e $80 \%$ no segundo, e 50 e $80 \%$ no terceiro.

Foram mantidas duas plantas em potes com $10 \mathrm{~kg}$ do horizonte B de um solo Podzólico Vermelho-Amarelo. Esse substrato apresenta maior teor de argila, causando portanto um dessecamento gradual do solo. Cada pote recebeu adubação equivalente a $60 \mathrm{~kg} / \mathrm{ha}$ de $\mathrm{K}_{2} \mathrm{O}, 100 \mathrm{~kg} / \mathrm{ha}$ de $\mathrm{P}_{2} \mathrm{O}_{5}$ e $2000 \mathrm{~kg} /$ ha de calcário dolomítico, e $10 \mathrm{~mL}$ por pote de uma solução de micronutrientes, com: $15,8 \mathrm{~g}$ de $\mathrm{CuSO}_{4} .5 \mathrm{H}_{2} \mathrm{O} ; 8,9 \mathrm{~g}$ de $\mathrm{ZnSO}_{4} .7 \mathrm{H}_{2} \mathrm{O} ; 0,3 \mathrm{~g}$ de $\mathrm{H}_{3} \mathrm{BO}_{3}$; $20 \mathrm{~g}$ de $\mathrm{FeSO}_{4} .7 \mathrm{H}_{2} \mathrm{O} ; 20 \mathrm{~g}$ de ácido cítrico; e $0,4 \mathrm{~g}$ de $\left(\mathrm{NH}_{4}\right)_{6} \mathrm{Mo}_{7} \mathrm{O}_{24} \cdot 4 \mathrm{H}_{2} \mathrm{O}$, por litro. As sementes foram inoculadas com uma mistura das estirpes $\mathrm{Br} 822, \mathrm{Br} 863$ e Br 868 de Rhizobium leguminosarum biovar phaseoli.

O déficit hídrico foi induzido pela suspensão da irrigação cinco dias anteriores à antese (estádio de botões florais), enquanto no tratamento irrigado esta foi mantida continuamente. $\mathrm{O}$ estresse hídrico foi imposto até que o potencial hídrico na folha $\left(\Psi_{\mathrm{f}}\right)$ atingisse valores em torno de -1,5 $\mathrm{MPa}$, considerado como limite para a recuperação do feijoeiro (Boyer, 1976). Após a indução do estresse, as plantas foram irrigadas até o final do ciclo.

$\mathrm{O}$ delineamento experimental foi fatorial completamente casualizado, com o número de potes determinado pelo número de genótipos vezes os tratamentos (com irrigação contínua e com estresse hídrico no estádio de pré-floração) 
vezes oito coletas (nos dias 0 e 2o, 4o $, 6^{\circ}, 8^{\circ}$ e $10^{\circ}$ de estresse; dois dias após a reidratação e no final do ciclo), vezes três repetições. No terceiro experimento não houve a coleta do décimo dia, pelo fato de as plantas terem sido irrigadas no oitavo dia. Neste experimento, as temperaturas médias do ambiente ficaram em torno de $40^{\circ} \mathrm{C}$, durante o período de estresse hídrico. Nos dois ensaios anteriores, as temperaturas médias do ambiente durante o estresse hídrico foram de 33 e $30^{\circ} \mathrm{C}$, respectivamente nesta ordem.

As amostras foram coletadas em plantas irrigadas continuamente (controle) e em plantas submetidas ao estresse. Nas coletas de amostras com 0,2, 4, 6, 8, 10 dias e com dois dias após a reidratação foram feitas as medições de $\Psi_{\text {f }}$, em discos retirados do folíolo central da folha mais jovem que tivesse atingido a sua expansão máxima, em plantas diferentes para cada repetição. As medições do potencial hídrico do solo $\left(\Psi_{\mathrm{s}}\right)$ foram feitas em cinco potes ao acaso, em cada tratamento. As médias desses valores de $\Psi_{\mathrm{s}}$ são apresentados nas Figs. 1, 2 e 3, juntamente com os valores de $\Psi_{\mathrm{f}}$, no intuito de mostrar-se o grau de dessecamento médio do solo.

As medidas de $\Psi_{\mathrm{f}}$ foram feitas nas plantas a serem avaliadas no dia da coleta, entre as 7 e as 10 horas da manhã. Para isso, foram utilizadas câmaras de medida C-52 acopladas a um microvoltímetro a ponto de orvalho (modelo HR-33T, da Wescor; USA). Nos dias de coleta foram medidos também os $\Psi_{\mathrm{s}}$ às 10 horas, com sensores PT-55 do mesmo equipamento, localizados a $0,15 \mathrm{~m}$ de profundidade, no centro do pote.

Nas coletas do dia 0 e dois dias após a reidratação, foram amostradas plantas inteiras, para contagem e pesagem de nódulos secos. Nesta última coleta, as plantas, estressadas ou não, foram avaliadas quanto às variáveis morfológicas: comprimento da raiz, peso seco da raiz, peso seco da parte aérea, relação raiz/parte aérea, e área foliar.

Os componentes de rendimento determinados nas plantas, estressadas ou não, no final do ciclo, foram: número de vagens/planta, número de grãos/planta e peso de grãos/planta.

$\mathrm{Na}$ análise de variância foi aplicado o teste $\mathrm{F}$, sendo que quando foi detectado efeito significativo, o teste de Student-Newman-Keuls, a 5\%, foi utilizado para a comparação das médias.

\section{RESULTADOS E DISCUSSÃO}

No primeiro experimento (Fig. 1), aos oito e dez dias após a suspensão da irrigação, o genótipo A 222 manteve o $\Psi_{\mathrm{f}}$ superior ao dos demais, e na reidratação, a cultivar Carioca recuperou-se rapidamente, atingindo maior $\Psi_{\mathrm{f}}$. Neste experimento, o $\Psi_{\mathrm{s}}$ médio atingiu -1,8 $\mathrm{MPa}$, e o $\Psi_{\mathrm{f}}$ dos genótipos foi inferior a -1,5 MPa, com dez dias de estresse, quando foi feita a reidratação. No segundo experimento (Fig. 2), aos quatro e seis dias de supressão hídrica, o genótipo A 285 manteve o $\Psi_{\mathrm{f}}$ significativamente superior, e a linhagem LM 10363, significativamente inferior ao dos demais genótipos; não houve, neste experimento, diferenças após a reidratação das plan-

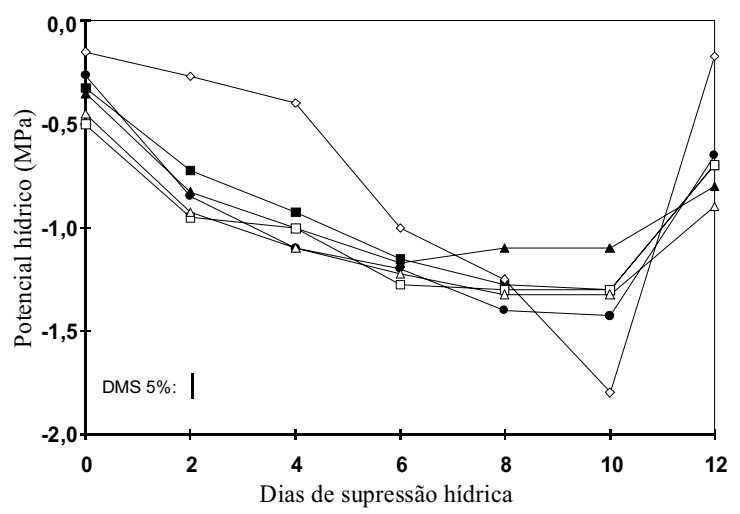

FIG. 1. Potencial hídrico médio $(\Psi)$ no solo $(\diamond)$ e na folha dos genótipos 2234 (口), A 222 (4), Carioca (๑), Negro Argel ( $\square$ ) e Xodó $(\triangle)$, cultivados nos meses de setembro a novembro de 1992 , em casa de vegetação.

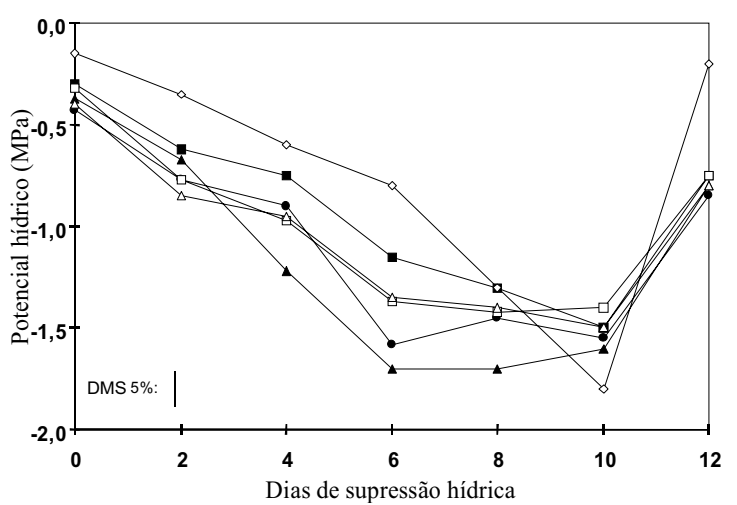

FIG. 2. Potencial hídrico médio $(\Psi)$ no solo $(\diamond)$ e na folha dos genótipos A 285 (口) e CNF $0145(\Delta)$ e das linhagens LM $10363(\Delta)$, LM 30036 (๑) e LM 30063 ( $\square$ ), cultivados nos meses de março a maio de $\mathbf{1 9 9 3}$, em casa de vegetação. 
tas, e o $\Psi_{\mathrm{s}}$ médio foi também de -1,8 $\mathrm{MPa}$, no décimo dia de déficit hídrico. No quarto dia de estresse do terceiro experimento (Fig. 3), o genótipo BAT 561 apresentou o $\Psi_{\mathrm{f}}$ significativamente superior ao do cv. 121, e no sexto dia, BAT 477, BAT 561 e IPA 7 apresentaram o $\Psi_{\mathrm{f}}$ significativamente superior aos valores de Ouro Negro, Xodó e cv. 121. Neste terceiro experimento, o dessecamento do solo aconteceu mais rapidamente, provavelmente em vista das altas temperaturas no ambiente e da menor umidade relativa do ar; o $\Psi_{\mathrm{s}}$ atingiu -1,5 $\mathrm{MPa}$ já no oitavo dia de estresse, e por isto, os vasos foram irrigados neste dia. Após a reidratação, a cultivar Ouro Negro apresentou $\Psi_{\mathrm{f}}$ significativamente superior ao dos demais genótipos, demonstrando maior capacidade de recuperação.

Nos três experimentos, os genótipos que se destacaram, mantendo maiores $\Psi_{\mathrm{f}}$, foram: A 222 , em estresse severo; A 285, em condições de déficit menos intenso; e BAT 477, BAT 561 e IPA 7, também sob moderado estresse. Na reidratação, as cultivares que se recuperaram mais rapidamente, apresentando $\Psi_{\mathrm{f}}$ superior ao dos demais genótipos, foram a Carioca e a Ouro Negro. Essa rápida capacidade de recuperação, observada nas cultivares Carioca e Ouro Negro, é uma característica desejável para a adaptação à seca (Boyer, 1976).

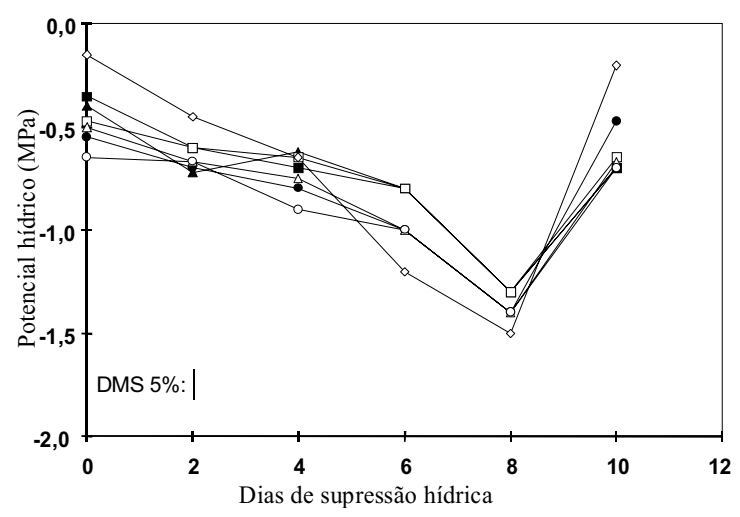

FIG. 3. Potencial hídrico médio $(\Psi)$ no solo $(\diamond)$ e na folha dos genótipos BAT 477 (), BAT 561 (A), Ouro Negro (๑), IPA $7(\square)$, Xodó $(\Delta)$ e cv. 121(O), cultivados nos meses de setembro a novembro de 1993, em casa de vegetação.
$\mathrm{O} \Psi_{\mathrm{f}}$ de sete genótipos foi avaliado em experimento anterior (Pimentel et al., 1990), e o genótipo A 320, que manteve o $\Psi_{\mathrm{f}}$ superior ao dos outros, foi posteriormente estudado sobre o efeito do estresse hídrico na condutância estomática (gs), na atividade fotossintética (A), e, conseqüentemente, na eficiência intrínseca do uso de água (A. $\left.\mathrm{gs}^{-1}\right)$. Neste último experimento, constatou-se que o genótipo A 320 fechou seus estômatos em menos tempo de déficit hídrico, mantendo assim o $\Psi_{\mathrm{f}}$ superior ao dos outros genótipos estudados (Pimentel, 1998). Portanto, os genótipos A 222, A 285, BAT 477, BAT 561 e IPA 7, que apresentaram menor redução

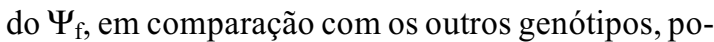
dem ter um maior controle do fechamento estomático; outras características, como a cutícula mais suberizada, ou ainda uma menor resistência hidráulica na raiz, por enraizamento profundo, exemplo do genótipo BAT 477, são consideradas importantes no estudo de tolerância à seca (Guimarães, 1996). As cultivares Carioca e Ouro Negro apresentaram outra característica desejável, a rápida recuperação após o déficit hídrico.

O genótipo A 320, já avaliado por Pimentel et al. (1990), e A 222 e A 285, todos genótipos resistentes às raças de antracnose na época de seus lançamentos, e possuidores do gene ARE, originário da cultivar Cornell 49-242 (Sartorato \& Rava, 1994), mantiveram também um alto $\Psi_{\mathrm{f}}$, denotando assim maior controle da abertura estomática. Portanto, os genótipos de feijoeiro resistentes à antracnose podem ter também o processo de fechamento estomático sensível tanto a elicitores produzidos na infecção pelo fungo, quanto a elicitores produzidos pelo estresse hídrico. A maioria dos genes de defesa vegetal pertencem a famílias multigênicas, cujos membros podem apresentar regulação diferencial em resposta a estímulos bióticos e abióticos (Bray,1993; Leite et al., 1997). Assim, o monitoramento de variáveis fisiológicas, indicadoras do controle da abertura estomática, poderá também ser útil na detecção de resistência a patógenos em plantas.

Nas coletas do dia 0 de estresse e dois dias de reidratação, foram amostradas plantas inteiras dos dois tratamentos, e avaliou-se o número e o peso seco de nódulos (Tabela 1). Houve boa nodulação em todos os genótipos, e aumento destes parâmetros 
avaliados entre as coletas antes do estresse (AE) e depois sem estresse (DSE). Na bibliografia, relata-se uma diminuição no número e peso de nódulos, causada pelo estresse hídrico (Pate, 1996); neste trabalho, foram detectadas diferenças significativas no segundo experimento, quanto ao peso seco de nódulos, exceto no genótipo CNF 0145, e no terceiro experimento, quanto ao número de nódulos, em todos os genótipos. A avaliação desses parâmetros de potencial de fixação biológica do $\mathrm{N}_{2}$, sem a medição da atividade da nitrogenase, parece não ter sido um bom indicador do efeito da falta d'água na fixação biológica do $\mathrm{N}_{2}$.

Dos parâmetros morfológicos mostrados na Tabela 2, os mais sensíveis à falta d'água foram a área foliar, com redução significativa nos três experimentos, e o peso seco da parte aérea, com redução em dois experimentos, o que confirma os resultados de Hsiao (1990). Blum (1997) ressalta que a diminuição da atividade fotossintética e da produtividade de plantas submetidas a déficit hídrico tem uma grande correlação com a redução da área foliar. Neste trabalho, a área foliar foi reduzida pelo estresse no genótipo 2234 no primeiro experimento; em A 285 e nas linhagens LM 10363 e LM 30036, no segundo experimento; e nos genótipos BAT 561, Ouro Negro, Xodó e cv. 121, no terceiro experimento. A cultivar Xodó não sofreu redução na área foliar no primeiro e no terceiro experimento, quando temperaturas médias ambientes de $40^{\circ} \mathrm{C}$ provocaram um dessecamento mais rápido. $\mathrm{O}$ peso seco da parte aérea só foi reduzido no segundo ensaio, nas linhagens LM 10363 e LM 30036, e no terceiro, nos genótipos Ouro Negro, Xodó e cv. 121. Portanto, entre os genótipos que mantiveram alto $\Psi_{\mathrm{f}}$ durante o estresse ou na reidratação, somente A 222 , BAT 477, IPA 7 e Carioca não sofreram redução na área foliar.

O efeito do estresse no desenvolvimento do sistema radicular foi avaliado através do peso seco das raízes, que no segundo experimento diminuiu mas não significativamente em A 285 e nas linhagens LM 10363 e LM 30036, e no terceiro experimento diminuiu significativamente nos genótipos BAT 561 e IPA 7. A relação raiz/parte aérea foi afetada nos dois últimos experimentos, devido, sobretudo, à am-

TABELA 1. Potencial de fixação biológica de nitrogênio (FBN) de quinze genótipos de feijoeiro, sob dois regimes hídricos, em três experimentos ${ }^{1}$.

\begin{tabular}{|c|c|c|c|c|c|c|}
\hline \multirow[t]{2}{*}{ Genótipo } & \multicolumn{3}{|c|}{ Número de nódulos } & \multicolumn{3}{|c|}{ Peso de nódulos (mg) } \\
\hline & $\mathrm{AE}$ & DSE & DCE & $\mathrm{AE}$ & DSE & DCE \\
\hline 2234 & 43 & $65 a$ & $35 \mathrm{a}$ & 45,9 & $71,0 \mathrm{a}$ & $30,4 a$ \\
\hline A 222 & 26 & $12 \mathrm{a}$ & $2 \mathrm{a}$ & 25,6 & $5,9 \mathrm{a}$ & $0,8 \mathrm{a}$ \\
\hline Carioca & 10 & $48 \mathrm{a}$ & $16 a$ & 2,6 & $82,5 \mathrm{a}$ & $2,1 \mathrm{a}$ \\
\hline Negro Argel & 36 & $18 \mathrm{a}$ & $26 a$ & 46,7 & $7,1 \mathrm{a}$ & $19,6 \mathrm{a}$ \\
\hline Xodó & 17 & $31 \mathrm{a}$ & $12 \mathrm{a}$ & 12,7 & $21,3 \mathrm{a}$ & 3,9a \\
\hline A 285 & 114 & $416 \mathrm{a}$ & $116 a$ & 86,8 & $600,9 b$ & $45,3 d$ \\
\hline LM 10363 & 520 & $678 \mathrm{a}$ & $345 \mathrm{a}$ & 572,8 & $998,8 \mathrm{a}$ & $202,2 \mathrm{c}$ \\
\hline LM 30036 & 451 & $441 \mathrm{a}$ & $153 a$ & 320,3 & $344,2 \mathrm{c}$ & $44,6 \mathrm{~d}$ \\
\hline LM 30063 & 220 & $276 a$ & $124 \mathrm{a}$ & 106,1 & $219,5 \mathrm{c}$ & $47,5 \mathrm{~d}$ \\
\hline CNF 0145 & 182 & $308 \mathrm{a}$ & $326 a$ & 120,3 & $219,9 \mathrm{c}$ & $189,9 \mathrm{c}$ \\
\hline BAT 477 & 59 & $70 b$ & $11 \mathrm{c}$ & 83,3 & $111,6 a$ & $15,0 \mathrm{a}$ \\
\hline BAT 561 & 34 & $147 \mathrm{ab}$ & $5 c$ & 26,6 & $100,0 \mathrm{a}$ & $3,3 \mathrm{a}$ \\
\hline Ouro Negro & 48 & $96 \mathrm{ab}$ & $9 c$ & 45,0 & $120,0 \mathrm{a}$ & $13,3 a$ \\
\hline IPA 7 & 56 & $103 \mathrm{ab}$ & $4 c$ & 46,6 & $83,3 a$ & $5,0 \mathrm{a}$ \\
\hline Xodó & 93 & $145 \mathrm{ab}$ & $13 \mathrm{c}$ & 96,6 & $166,6 a$ & $18,3 \mathrm{a}$ \\
\hline Cv. 121 & 51 & $200 \mathrm{a}$ & $8 \mathrm{c}$ & 40,0 & $100,0 \mathrm{a}$ & $11,6 \mathrm{a}$ \\
\hline
\end{tabular}


plitude de variação do peso seco da parte aérea. Em vaso, a imposição rápida do estresse, associada a um possível bloqueio do crescimento da raiz ao atingir o fundo do recipiente, poderia impedir o crescimento desta, alterando a resposta ao déficit hídrico. Sugere-se que esses parâmetros sejam avaliados em experimentos no campo.
O peso de grãos/planta diminuiu significativamente com o estresse hídrico, nos três experimentos (Tabela 3), o que confirma os dados de Fageria et al. (1991) e Guimarães (1996). No primeiro ensaio, houve redução na cultivar Carioca; no segundo, nos genótipos A 285 e CNF 0145 e na linhagem LM 30036; e no terceiro, nos genótipos BAT 477 e

TABELA 2. Variáveis morfológicas de quinze genótipos de feijoeiro, sob dois regimes hídricos, em três experimentos ${ }^{1}$.

\begin{tabular}{|c|c|c|c|c|c|}
\hline Genótipo & Tratamento & $\begin{array}{l}\text { Peso seco } \\
\text { de raiz }(\mathrm{g})\end{array}$ & $\begin{array}{l}\text { Peso seco da } \\
\text { parte aérea }(\mathrm{g})\end{array}$ & $\begin{array}{c}\text { Relação } \\
\text { raiz/parte aérea }\end{array}$ & $\begin{array}{c}\text { Área foliar } \\
\left(\mathrm{m}^{2}\right)\end{array}$ \\
\hline & \multicolumn{5}{|c|}{ Setembro a novembro de 1992} \\
\hline \multirow[t]{2}{*}{2234} & Controle & $1,3 \mathrm{a}$ & $3,7 \mathrm{a}$ & $0,34 \mathrm{a}$ & $0,059 \mathrm{a}$ \\
\hline & Estresse & $1,1 \mathrm{a}$ & $2,6 a$ & $0,44 \mathrm{a}$ & $0,021 \mathrm{~b}$ \\
\hline \multirow[t]{2}{*}{ A 222} & Controle & $0,7 \mathrm{a}$ & $1,3 \mathrm{a}$ & $0,57 \mathrm{a}$ & $0,061 \mathrm{~b}$ \\
\hline & Estresse & $0,6 \mathrm{a}$ & $1,3 \mathrm{a}$ & $0,42 \mathrm{a}$ & $0,088 \mathrm{~b}$ \\
\hline \multirow[t]{2}{*}{ Carioca } & Controle & $0,5 \mathrm{a}$ & $2,4 a$ & $0,22 \mathrm{a}$ & $0,035 \mathrm{ab}$ \\
\hline & Estresse & $0,4 \mathrm{a}$ & $2,0 \mathrm{a}$ & $0,18 \mathrm{a}$ & $0,053 b$ \\
\hline \multirow[t]{2}{*}{ Negro Argel } & Controle & $0,8 \mathrm{a}$ & $1,9 \mathrm{a}$ & $0,43 \mathrm{a}$ & $0,029 \mathrm{ab}$ \\
\hline & Estresse & $0,6 \mathrm{a}$ & $1,2 \mathrm{a}$ & $0,45 \mathrm{a}$ & $0,014 \mathrm{~b}$ \\
\hline \multirow[t]{3}{*}{ Xodó } & Controle & $0,4 \mathrm{a}$ & $1,2 \mathrm{a}$ & $0,34 \mathrm{a}$ & $0,061 b$ \\
\hline & Estresse & $0,5 \mathrm{a}$ & $1,0 \mathrm{a}$ & $0,47 \mathrm{a}$ & $0,051 b$ \\
\hline & \multicolumn{5}{|c|}{ Marcco a maio de 1993} \\
\hline \multirow[t]{2}{*}{ A 285} & Controle & $2,6 \mathrm{a}$ & $6,5 c$ & $0,40 \mathrm{a}$ & $0,183 \mathrm{ab}$ \\
\hline & Estresse & $2,1 \mathrm{a}$ & $3,9 \mathrm{~cd}$ & $0,52 \mathrm{a}$ & $0,032 \mathrm{c}$ \\
\hline \multirow[t]{2}{*}{ LM 10363} & Controle & $2,5 \mathrm{a}$ & $13,8 \mathrm{a}$ & $0,18 b$ & $0,199 \mathrm{a}$ \\
\hline & Estresse & $1,9 \mathrm{a}$ & $5,1 \mathrm{~cd}$ & $0,38 \mathrm{a}$ & $0,072 \mathrm{bc}$ \\
\hline \multirow[t]{2}{*}{ LM 30036} & Controle & $1,5 \mathrm{a}$ & $10,3 b$ & $0,15 b$ & $0,159 \mathrm{ab}$ \\
\hline & Estresse & $1,7 \mathrm{a}$ & $3,7 \mathrm{~cd}$ & $0,47 \mathrm{a}$ & $0,045 \mathrm{c}$ \\
\hline \multirow[t]{2}{*}{ LM 30063} & Controle & $2,0 \mathrm{a}$ & $2,0 \mathrm{~d}$ & $1,0 \mathrm{a}$ & $0,115 \mathrm{abc}$ \\
\hline & Estresse & $2,1 \mathrm{a}$ & $4,2 \mathrm{~cd}$ & $0,50 \mathrm{a}$ & $0,068 \mathrm{bc}$ \\
\hline \multirow[t]{3}{*}{ CNF 0145} & Controle & $1,9 \mathrm{a}$ & $1,9 \mathrm{~d}$ & $1,0 \mathrm{a}$ & $0,151 \mathrm{ab}$ \\
\hline & Estresse & $2,0 \mathrm{a}$ & $5,1 \mathrm{~cd}$ & $0,40 \mathrm{a}$ & $0,076 b c$ \\
\hline & \multicolumn{5}{|c|}{ Setembro a novembro de 1993} \\
\hline \multirow[t]{2}{*}{ BAT 477} & Controle & $1,2 \mathrm{abc}$ & $2,7 \mathrm{bcd}$ & $0,43 \mathrm{a}$ & $0,051 \mathrm{bcd}$ \\
\hline & Estresse & $0,7 \mathrm{~cd}$ & $1,5 \mathrm{~d}$ & $0,46 \mathrm{a}$ & $0,019 \mathrm{~cd}$ \\
\hline \multirow[t]{2}{*}{ BAT 561} & Controle & $1,5 \mathrm{a}$ & $2,8 \mathrm{bcd}$ & $0,53 \mathrm{a}$ & $0,058 \mathrm{abc}$ \\
\hline & Estresse & $0,7 \mathrm{~cd}$ & $1,2 \mathrm{~d}$ & $0,54 \mathrm{a}$ & $0,018 \mathrm{~d}$ \\
\hline \multirow[t]{2}{*}{ Ouro Negro } & Controle & $1,1 \mathrm{abc}$ & $4,9 \mathrm{a}$ & $0,23 b$ & $0,089 \mathrm{a}$ \\
\hline & Estresse & $0,6 \mathrm{~cd}$ & $1,6 \mathrm{~d}$ & $0,40 \mathrm{a}$ & $0,026 \mathrm{~cd}$ \\
\hline \multirow[t]{2}{*}{ IPA 07} & Controle & $1,3 \mathrm{ab}$ & $2,8 \mathrm{bcd}$ & $0,47 \mathrm{a}$ & $0,058 \mathrm{abc}$ \\
\hline & Estresse & $0,8 \mathrm{~cd}$ & $1,4 \mathrm{~d}$ & $0,58 \mathrm{a}$ & $0,024 \mathrm{~cd}$ \\
\hline \multirow[t]{2}{*}{ Xodó } & Controle & $1,1 \mathrm{abc}$ & $4,4 \mathrm{ab}$ & $0,24 b$ & $0,073 \mathrm{ab}$ \\
\hline & Estresse & $0,7 \mathrm{~cd}$ & $2,1 \mathrm{~cd}$ & $0,34 \mathrm{ab}$ & $0,035 \mathrm{~cd}$ \\
\hline \multirow[t]{2}{*}{ Cv. 121} & Controle & $0,9 \mathrm{bcd}$ & $3,8 \mathrm{abc}$ & $0,24 b$ & $0,082 \mathrm{ab}$ \\
\hline & Estresse & $0,5 \mathrm{~d}$ & $1,4 \mathrm{~d}$ & $0,38 \mathrm{a}$ & $0,019 \mathrm{~cd}$ \\
\hline
\end{tabular}

1 Médias (três repetições) seguidas por letras diferentes, na mesma variável dentro de cada um dos três experimentos, diferem entre si significativamente pelo teste Student-Newman-Keuls (5\%). 
cv. 121. Quanto ao número de vagens/planta, houve efeito significativo nos genótipos Xodó e CNF 0145, nos dois primeiros experimentos. O número de grãos/planta sofreu redução no primeiro experimento, na cultivar Carioca, e no segundo experimento, nos genótipos A 285, CNF 0145 e LM 30036. Comparando-se os ensaios, no terceiro experimento houve menor produção de vagens e de grãos do que nos dois outros, provavelmente devido ao efeito de altas temperaturas ambientes (média de $40^{\circ} \mathrm{C}$ ). Tais temperaturas ambientes são consideradas muito altas para o feijoeiro e, sobretudo quando ocorrem na pré-floração, causam redução no número de vagens e grãos (Norman et al., 1995).

TABELA 3. Componentes de rendimento de quinze genótipos de feijoeiro, sob dois regimes hídricos, em três experimentos ${ }^{1}$.

\begin{tabular}{|c|c|c|c|c|}
\hline Genótipo & Tratamento & $\begin{array}{l}\text { Vagens/planta } \\
\text { (n) }\end{array}$ & $\begin{array}{c}\text { Grãos/planta } \\
\text { (n) }\end{array}$ & $\begin{array}{c}\text { Peso de } \\
\text { grãos/planta (g) }\end{array}$ \\
\hline & \multicolumn{4}{|c|}{ Setembro a novembro de 1992} \\
\hline \multirow[t]{2}{*}{2234} & Controle & $6 a$ & $12 \mathrm{bc}$ & $5,64 a b$ \\
\hline & Estresse & $5 b$ & $11 \mathrm{bc}$ & $2,06 \mathrm{bc}$ \\
\hline \multirow[t]{2}{*}{ A 222} & Controle & $4 b$ & $3 \mathrm{de}$ & $1,86 b c$ \\
\hline & Estresse & $2 b$ & $1 \mathrm{e}$ & $0,05 \mathrm{c}$ \\
\hline \multirow[t]{2}{*}{ Carioca } & Controle & $5 b$ & $22 \mathrm{a}$ & $7,72 \mathrm{a}$ \\
\hline & Estresse & $3 b$ & $6 \mathrm{cde}$ & $2,70 \mathrm{bc}$ \\
\hline \multirow[t]{2}{*}{ Negro Argel } & Controle & $6 \mathrm{~b}$ & $9 \mathrm{bc}$ & $2,64 b c$ \\
\hline & Estresse & $5 \mathrm{~b}$ & $7 \mathrm{~cd}$ & $1,58 \mathrm{bc}$ \\
\hline \multirow[t]{3}{*}{ Xodó } & Controle & $11 \mathrm{a}$ & $18 \mathrm{ab}$ & $5,18 \mathrm{ab}$ \\
\hline & Estresse & $3 b$ & $8 \mathrm{bcd}$ & $3,62 \mathrm{abc}$ \\
\hline & \multicolumn{4}{|c|}{ Março a maio de 1993} \\
\hline \multirow[t]{2}{*}{ A 285} & Controle & $13 b$ & $51 \mathrm{a}$ & $9,93 \mathrm{a}$ \\
\hline & Estresse & $10 \mathrm{~b}$ & $15 \mathrm{bc}$ & $1,77 b c$ \\
\hline \multirow[t]{2}{*}{ LM 10363} & Controle & $14 \mathrm{ab}$ & $50 \mathrm{ab}$ & $8,80 \mathrm{ab}$ \\
\hline & Estresse & $7 \mathrm{~b}$ & $27 \mathrm{~b}$ & $4,77 b c$ \\
\hline \multirow[t]{2}{*}{ LM 30036} & Controle & $14 \mathrm{ab}$ & $30 \mathrm{ab}$ & $5,37 \mathrm{ab}$ \\
\hline & Estresse & $8 \mathrm{~b}$ & $12 \mathrm{~cd}$ & $1,23 \mathrm{c}$ \\
\hline \multirow[t]{2}{*}{ LM 30063} & Controle & $10 \mathrm{~b}$ & $26 \mathrm{~b}$ & $4,20 \mathrm{bc}$ \\
\hline & Estresse & $6 b$ & $15 \mathrm{bc}$ & $1,80 \mathrm{bc}$ \\
\hline \multirow[t]{3}{*}{ CNF 0145} & Controle & $18 \mathrm{a}$ & $18 \mathrm{bc}$ & $11,50 \mathrm{a}$ \\
\hline & Estresse & $7 b$ & $2 \mathrm{~d}$ & $2,70 \mathrm{bc}$ \\
\hline & \multicolumn{4}{|c|}{ Setembro a novembro de 1993} \\
\hline \multirow[t]{2}{*}{ BAT 477} & Controle & $3 \mathrm{a}$ & $5 \mathrm{ab}$ & $1,18 \mathrm{a}$ \\
\hline & Estresse & $1 \mathrm{a}$ & $2 b$ & $0,36 b c$ \\
\hline \multirow[t]{2}{*}{ BAT 561} & Controle & 1a & $2 b$ & $0,39 b c$ \\
\hline & Estresse & $1 \mathrm{a}$ & $1 b$ & $0,07 \mathrm{c}$ \\
\hline \multirow[t]{2}{*}{ Ouro Negro } & Controle & $2 \mathrm{a}$ & $3 a b$ & $0,41 b c$ \\
\hline & Estresse & $1 \mathrm{a}$ & $3 a b$ & $0,48 \mathrm{ab}$ \\
\hline \multirow[t]{2}{*}{ IPA 7} & Controle & 1a & $2 \mathrm{~b}$ & $0,37 \mathrm{bc}$ \\
\hline & Estresse & $1 \mathrm{a}$ & $3 a b$ & $0,48 \mathrm{ab}$ \\
\hline \multirow[t]{2}{*}{ Xodó } & Controle & $2 \mathrm{a}$ & $7 \mathrm{a}$ & $1,29 \mathrm{a}$ \\
\hline & Estresse & 1a & $6 a b$ & $1,06 \mathrm{a}$ \\
\hline \multirow[t]{2}{*}{ Cv. 121} & Controle & $2 a$ & $4 a b$ & $0,67 a b$ \\
\hline & Estresse & $1 \mathrm{a}$ & $1 b$ & $0,22 \mathrm{c}$ \\
\hline
\end{tabular}

1 Médias (três repetições) seguidas por letras diferentes, na mesma variável dentro de cada um dos três experimentos, diferem entre si significativamente pelo teste Student-Newman-Keuls (5\%). 
Em casa de vegetação, apesar do ambiente protegido, as variações de fatores climáticos, sobretudo da temperatura, afetam diferentemente o desenvolvimento das plantas, dificultando a comparação de resultados de experimentos em épocas distintas.

Os genótipos A 222, A 285, BAT 477, BAT 561 e IPA 7 mantiveram seus $\Psi_{\mathrm{f}}$ superiores ao dos demais, e as cultivares Carioca e Ouro Negro apresentaram uma rápida recuperação do $\Psi_{\mathrm{f}}$. Entre esses, somente A 222, BAT 561, Ouro Negro e IPA 7 não tiveram uma redução significativa na produção de grãos. Entretanto, os genótipos A 222 e BAT 561, apesar de manterem alto $\Psi_{\mathrm{f}}$, tiveram baixa produtividade, um fenômeno considerado comum em plantas adaptadas à seca. Segundo Kramer \& Boyer (1995), a medição do $\Psi_{\mathrm{f}}$ ou do conteúdo hídrico relativo, para avaliar a manutenção de alto status hídrico, é um bom indicador de tolerância à seca, e uma conseqüência dos mecanismos de adaptação à deficiência hídrica, tais como o controle da abertura estomática e/ou menor densidade estomática, a suberização e produção de cera na cutícula, ou a menor resistência hidráulica da raiz.

Entre as variáveis estudadas, o $\Psi_{\mathrm{f}}$, a área foliar e o peso seco da parte aérea foram os melhores indicadores do efeito do estresse hídrico no feijoeiro. Tais parâmetros, inicialmente bastante utilizados como indicadores de tolerância à seca (Boyer, 1976), foram substituídos por parâmetros mais sofisticados, como a acumulação de prolina, glicina-betaína, e outros compostos (Hanson \& Hitz, 1982), ou a discriminação isotópica do carbono e técnicas de biologia molecular (Subbarao et al., 1995). Contudo, em uma avaliação recente sobre os ganhos de produtividade em condições de deficiência hídrica, Blum (1997) recomenda o uso de parâmetros, como a área foliar e o $\Psi_{\mathrm{f}}($ Kramer \& Boyer, 1995). Esses parâmetros estão diretamente correlacionados com a produtividade, e propiciam o estudo do comportamento de genótipos de diferentes procedências ou de raças distintas (Norman et al., 1995).

\section{CONCLUSÕES}

1. O monitoramento do $\Psi_{\mathrm{f}}$ e da área foliar durante e após o estresse hídrico, associado à avaliação do rendimento da cultura, em casa de vegetação apresenta-se como bom indicador de tolerância à seca no feijoeiro.

2. A avaliação do sistema radicular em casa de vegetação não é recomendável como parâmetro indicador de tolerância à deficiência hídrica.

\section{REFERÊNCIAS}

BLUM, A. Crop responses to drought and the interpretation of adaptation. In: BELHASSEN, E. (Ed.). Drought tolerance in higher plants: genetical, physiological, and molecular biology analysis. Dordrecht : Kluwer Academic, 1997. p.57-70.

BOYER, J.S. Water deficits and photosynthesis. In: KOZLOWSKI, T.T. (Ed.). Water deficits and plant growth. New York : Academic, 1976. v.4, p.153-190.

BRAY, E.A. Update on water deficit. Molecular responses to water déficit. Plant Physiology, Bethesda, v.103, p.1035-1040, 1993.

FAGERIA, N.K.; BALIGAR, V.C.; JONES, C.A. Common bean and cowpea. In: FAGERIA, N.K.; BALIGAR, V.C.; JONES, C.A. (Eds.). Growth and mineral nutrition of field crops. New York : Marcel Dekker, 1991. p.280-318.

GUIMARÃES, C.M. Relações hídricas. In: ARAÚJO, R.S.; RAVA, C.A.; STONE, L.F.; ZIMMERMANN, M.J. de O. (Eds.). Cultura do feijoeiro comum no Brasil. Piracicaba : Potafos, 1996. p.139-168.

HANSON, A.D.; HITZ, W.D. Metabolic responses of mesophytes to plant water deficits. Annual Review of Plant Physiology, Bethesda, v.33, p.163-203, 1982.

HSIAO, T.C. Measurements of plant water status. In: STEWART, B.A.; NIELSEN, D.R. (Eds.). Irrigation of agricultural crops. New York : American Society of Agronomy, 1990. ch.9, p.244-280.

KRAMER, P.J.; BOYER, J.S. Evolution and agriculture. In: KRAMER, P.J.; BOYER, J.S. (Eds.). Water relations of plants and soils. San Diego : Academic, 1995. p.377-404.

KURUVADI, S.; AGUILERA, D.M. Patrones del sistema radicular en frijol común (Phaseolus vulgaris L.). Turrialba, San José, v.40, p.491-498, 1990. 
LEITE, B.; RONCATO, L.D.B.; PASCHOLATI, S.F.; LAMBAIS, M.R. Reconhecimento e transdução de sinais moleculares em interações planta-fungos patogênicos. Revisão Anual de Patologia de Plantas, Passo Fundo, v.5, p.235-280, 1997.

NORMAN, M.J.T.; PEARSON, C.J.; SEARLE, P.G.E. Common bean (Phaseolus vulgaris L.). In: NORMAN, M.J.T.; PEARSON, C.J.; SEARLE, P.G.E. (Eds.). The ecology of tropical food crops. Cambridge : Cambridge University Press, 1995. p.208-224.

O’TOOLE, J.C.; OZBUN, J.L.; WALLACE, D.H. Photosynthetic response to water stress in Phaseolus vulgaris L. Physiologia Plantarum, Copenhagen, v.40, p.111-114, 1977.

PATE, J.S. Photoassimilate partitioning and consumption in nitrogen-fixing crop legumes. In: ZAMSKI, E.; SCHAFFER, A.A. (Eds.). Photoassimilate distribution in plants and crops. Source-Sink relationships. New York : Marcel Dekker, 1996. p.467-478.

PIMENTEL, C. Metabolismo de carbono na agricultura tropical. Seropédica : EDUR, 1998. 159p.
PIMENTEL, C.; JACOB NETO, J.; GOI, S.R.; PESSANHA, G.G. Estresse hídrico em cultivares de Phaseolus vulgaris L. em simbiose com o Rhizobium leguminosarum biovar phaseoli. Turrialba, San José, v.40, p.520-526, 1990.

PORTES, T. de A. Ecofisiologia. In: ARAÚJO, R.S.; RAVA, C.A.; STONE, L.F.; ZIMMERMANN, M.J. de O. (Coords.). Cultura do feijoeiro comum no Brasil. Piracicaba : Potafos, 1996. p.101-168.

SARTORATO, A.; RAVA, C.A. Antracnose. In: SARTORATO, A.; RAVA, C.A. (Eds.). Principais doenças do feijoeiro comum e seu controle. Brasília : Embrapa-SPI, 1994. p.17-40. (EmbrapaCNPAF. Documentos, 50).

SINGH, S.P. Selection for water-stress tolerance in interracial populations of common bean. Crop Science, Madison, v.35, p.118-124, 1995.

SUBBARAO, G.V.; JOHANSEN, A.C.; SLINKARD, R.C.; RAO, N.; SAXENA, N.P.; CHAUHAN, Y.S. Strategies for improving drought resistance in grain legumes. Critical Review in Plant Science, Pearl River, v.14, p.469-529, 1995. 